\title{
O PRONOME OBLÍQUO DE TERCEIRA PESSOA: INVESTIGAÇÃO PSICOLINGUÍSTICA DE OBSERVAÇÕES PRAGMÁTICAS NO PAR PORTUGUÊS BRASILEIRO/ESPANHOL
}

\author{
THE THIRD PERSON OBLIQUE PRONOUN: A PSYCHOLINGUISTIC INVESTIGATION \\ ON PRAGMATIC OBSERVATIONS WITHIN THE LANGUAGE PAIR BRAZILIAN \\ PORTUGUESE/SPANISH
}

\author{
Lílian Rodrigues de Almeida \\ Universidade Federal de Minas Gerais
}

\begin{abstract}
RESUMO: O pronome oblíquo como anáfora de objeto direto é item gramatical comum ao português brasileiro e ao espanhol, sendo o uso na língua diferenciado por efeitos pragmáticos. Com o objetivo de avaliar se a pragmática geraria, para os falantes do português brasileiro, efeito de estranhamento na leitura desse item, criou-se uma tarefa na qual cada falante leu, em sua língua materna, uma série de pares de frases no meio das quais constava essa estrutura crítica. O resultado mostrou-se oposto à hipótese, tendo sido os falantes nativos do espanhol os sujeitos que apresentaram maior média de tempo de fixação na estrutura avaliada. Sugeriu-se, como justificativa, a possível influência do português brasileiro na percepção dos estrangeiros de sua própria língua, uma influência que estaria relacionada ao tempo de inserção nessa nova língua.
\end{abstract}

PALAVRAS-CHAVE: português brasileiro; espanhol; pronome oblíquo de objeto direto; pragmática; rastreamento ocular.

ABSTRACT: The oblique pronoun as an anaphor in direct object position is a grammatical item common to both Brazilian Portuguese and Spanish, its use being different in each language according to pragmatic effects. Aiming at assessing if pragmatics would cause, to Brazilian Portuguese speakers, a "strangement" effect when they read this item, the researches created a task in which each speaker read, in one's own maternal language, a series of pairs of phrases among which was this critical structure. The result found was contrary to the hypothesis, the Spanish speakers being the ones who showed the biggest mean time of fixation on the assessed structure. The researchers suggest, as an explanation, that the Brazilian Portuguese is probably influencing on the foreigner's own language perception, a kind of influence that would be connected to their insertion time in the new language.

KEYWORDS: Brazilian Portuguese; Spanish; oblique pronoun as direct object; pragmatics; eye-tracking.

\section{Introdução}

O espanhol e o português são línguas neolatinas irmãs. A proximidade geográfica dos territórios em que nasceram as línguas, além do período em que a Península lbérica sofreu a invasão do Império Romano, por volta do 3o século a.C. (PENNY, 1995), 


\section{Revista do SELL}

v. $4, n^{\circ} .1$

ISSN: $1983-3873$

explicam as semelhanças, principalmente na estrutura gramatical e no léxico (RODRÍGUEZ, 2004). Há, entretanto, importantes diferenças, muitas das quais de ordem pragmática. Uma delas, o uso da anáfora "pronome de objeto direto" será alvo de investigação neste trabalho.

Anáforas são expressões que fazem menção a um referente, um antecedente encontrado no mesmo discurso (GELORMINI-LEZAMA; ALMOR, 2011). Elas evitam a repetição desse referente e dão coesão ao texto (GELORMINI-LEZAMA; ALMOR, 2011). Com relação à anáfora de pronome de objeto direto, ao comparar-se o português brasileiro e o espanhol, percebe-se que embora haja correspondência sintática e semântica nessa estrutura, a pragmática distingue a frequência de ocorrência em seu uso. Segundo Moreno Garcia e Fernández (2007), a língua espanhola exige o uso de pronomes de objeto, direto ou indireto, como pronome anafórico na função de objeto direto. Ou seja, não se aceita, por exemplo, que pronomes sujeito cumpram essa função. O pronome de objeto é tão natural para os falantes da língua que é possível e inclusive comum o emprego simultâneo desses pronomes na frase, um de objeto direto, o outro de indireto; em português brasileiro esse uso só se encontraria na língua escrita literária (MORENO GARCIA; FERNÁNDEZ, 2007).

O uso de pronomes de objeto como anáfora não é preferência entre os brasileiros. Na língua oral, na maioria das ocorrências, os referentes são repetidos, não substituídos (MORENO GARCIA; FERNÁNDEZ, 2007). Na língua escrita, na presença de ambos os objetos, direto e indireto, a opção mais frequente é substituir apenas um deles pela anáfora correspondente (MORENO GARCIA; FERNÁNDEZ, 2007), geralmente o objeto indireto (COELHO, 2001). Há, ainda, outro fenômeno tipicamente brasileiro, que consiste no emprego de pronomes sujeito ou de pronome nulo como anáfora para a função de objeto. Esses fenômenos, que diferenciam o português brasileiro do europeu, cujo emprego de pronomes assemelha-se ao espanhol, já apresentariam registro entre os séculos XIX e início do XX (CYRINO, 1996; OLIVEIRA, 2010).

Essas observações pragmáticas podem se valer a diferentes linhas de pesquisa. Uma delas é a tradução, em que se prima pela fidelidade (SAEZ HERMOSILLA, 1994; ADAMO, 2004), entendida não apenas como fidelidade ao sentido ou transcrição léxica, mas, na medida do possível, ao estilo dos autores (ECO, 2009). Outra, foco deste estudo, é o processamento da linguagem. As manifestações linguísticas guiadas pela pragmática mostraram-se um rico material de estudo nesse domínio. 


\section{Revista do SELL}

v. $4, n^{\circ} .1$

ISSN: $1983-3873$

A frequência de ocorrência do pronome de objeto, especialmente o de terceira pessoa, é marcadamente diferente entre o português brasileiro e o espanhol, como se pode depreender de observações relatadas na literatura. Decidiu-se, então, investigar se o processamento dessa estrutura linguística diferia entre os grupos de falantes.

Com uma tarefa de leitura, a expectativa era obter maior tempo de processamento no grupo de brasileiros, falantes menos habituados à estrutura testada. Para isso, empregou-se a técnica do rastreamento ocular, uma técnica de avaliação do processamento visual que vem sendo utilizada por psicolinguistas (RAYNER; LIVERSEDGE, 2004). Ela permite uma análise online do processamento, ou seja, no momento em que ocorre (KLEIN; BULLA, 2010). Para as medições, a técnica apresenta diversos parâmetros. Neste estudo, trabalhou-se com a "fixação", que corresponde ao tempo que o olhar permanece dirigido a um ponto da imagem ou texto (HENDERSON; FERREIRA, 2004).

Os movimentos oculares vêm sendo estudados como ferramentas de detecção e avaliação do processamento de informações. Eles têm sido recurso importante para a compreensão da linguagem em vários ramos, como o semântico, o lexical, o sintático e o fonético-fonológico, com tarefas como as que relacionam imagens a comandos linguísticos (TANENHAUS et al., 1995; HUETTIG; ALTMANN, 2005) ou as de leitura (RAYNER; WELL, 1996; MCDONALD; SHILLCOCK, 2003; YOKOMIZO et al., 2008; OGUSUKO; LUKASOVA; MACEDO, 2008; TRAUZETTEL-KLOSINSKI et al., 2010; JAINTA; KAPOULA, 2011; FILIK; BARBER; 2011).

Além dos recursos de imagem e leitura para a compreensão da linguagem com o uso do rastreamento ocular para a análise dos dados, a comparação entre línguas tem se mostrado de grande interesse científico. Duas estimativas principais são investigadas nesse tipo de pesquisa. As semelhanças entre as línguas indicariam um denominador comum, que é o fato de serem elas uma manifestação da capacidade humana de linguagem, com supostas leis maiores unificadoras de qualquer código linguístico. Em uma escala menor, as semelhanças poderiam, ainda, indicar a proximidade entre as línguas, em termos históricos ou geográficos, dentre outros. Frente às diferenças, os cientistas investigam as especificidades desses códigos e especulam suas causas, o que é o objetivo do presente trabalho. A literatura especializada mostra a busca por essas respostas na comparação de vários pares linguísticos, como o inglês e o chinês (SUN; MORITA; STARK, 1985; RAYNER et al., 2005; YANG et al., 1999), o inglês e o português 


\section{Revista do SELL}

v. $4, n^{\circ} .1$

ISSN: $1983-3873$

(MACEDO et al., 2007) e o inglês e o alemão (TRAUZETTEL-KLOSINSKI et al., 2010). $O$ presente trabalho se propôs a comparar o português e o espanhol.

Com relação às estruturas frasais analisadas nos estudos psicolinguísticos, na leitura, aquelas que atuam como anáfora são um dos tipos que mais suscitam indagações, e o rastreamento ocular é a principal ferramenta para sua investigação. Muitos estudos foram feitos para comparar o processamento de diferentes tipos de anáfora para um mesmo referente (GERNSBACHER, 1989; GORDON et al., 1993; ALMOR, 1999; YANG et al., 1999; GELORMINI-LEZAMA; ALMOR, 2011; MAIA; CUNHA LIMA (2012); COSTA; MATOS; LUEGI, 2011). No presente estudo, a proposta é comparar, com o rastreamento ocular, o processamento de um mesmo tipo de anáfora, o pronome de objeto direto, entre duas línguas, o português brasileiro e o espanhol.

Como sugerem Rayner e Liversedge (2004), o rastreamento ocular é provavelmente a melhor forma já desenvolvida para estudar o processamento de pronomes. Além disso, o efeito de estranhamento de cunho pragmático, provocado por uma estrutura inabitual, medido por uma avaliação online do processamento da linguagem, e, sobretudo, nesse par linguístico, o português/espanhol, é um tópico pouco explorado na literatura. O presente trabalho representa, assim, uma contribuição para o desenvolvimento das pesquisas nesse âmbito da psicolinguística.

A hipótese sustentada pelo estudo é a seguinte: os pronomes oblíquos de terceira pessoa como anáfora de objeto são processados com mais dificuldade por falantes nativos do português brasileiro, em leitura de texto nessa língua, que por falantes nativos do espanhol, lendo em sua respectiva língua, devido ao estranhamento provocado pelo fator pragmático, pois dita estrutura tem menor uso no português brasileiro. Diante dessa hipótese, a pesquisa visou a verificar se os achados subjetivos podiam ser comprovados por uma avaliação objetiva, por meio da medição feita com o rastreador ocular. Avaliaramse o tempo e o número de fixações no pronome de objeto direto anafórico, ao que se seguiu uma análise comparativa entre os grupos.

\section{Metodologia}

\subsection{Participantes}

Os participantes formavam dois grupos de sujeitos adultos. Um dos grupos constituiu-se de 5 falantes nativos do português brasileiro. $O$ outro grupo foi formado por 5 


\section{Revista do SELL \\ v. $4, n^{\circ} .1$ \\ ISSN: $1983-3873$}

falantes nativos da língua espanhola, cuja distribuição por origem foi: 3 argentinos, 1 peruano e 1 paraguaio. Não foram recrutados espanhóis de modo a evitar que o fenômeno do leísmo (uso de "le(s)", pronome de objeto indireto de terceira pessoa, no lugar de "la/o(s)", pronome de objeto direto de terceira pessoa quando o referente a que se faz menção é uma pessoa), próprio desses sujeitos, pudesse ser variável provocadora de diferença de processamento dos pronomes oblíquos de terceira pessoa dentro do grupo. Os sujeitos da pesquisa eram universitários ou profissionais com nível superior. Em relação aos participantes estrangeiros, a média de tempo em que vivem no Brasil é de 14,5 anos, variando entre 5 e 28 anos.

\subsection{Procedimentos}

\subsubsection{Material}

Preparou-se uma lista de 108 pares de frases, traduzida para cada uma das línguas do estudo, o português brasileiro e o espanhol. O par consistia em frases de estrutura SVO (sujeito-verbo-objeto) em que na primeira constavam os referentes (apenas sujeito, nas frases com verbos intransitivos, ou sujeito e objeto naquelas com verbo transitivo) e, na segunda, chamada frase crítica, as anáforas. Nos casos em que a ambiguidade pudesse interferir na interpretação da anáfora, dificultando a adequada correlação entre o pronome e o antecedente, os referentes das primeiras frases eram necessariamente de gêneros diferentes. As frases críticas ora mantinham a função sintática do referente, ora não.

Havia pares alvo e pares distratores. Segundo Fernández e Cairns (2010), esses dois tipos de material geralmente fazem parte dos experimentos em Psicolinguística. Os pares de frases do tipo alvo, explicam as autoras, são aqueles que contêm a estrutura de interesse para a hipótese do estudo, i.e., a estrutura crítica. Os pares distratores, por sua vez, são utilizados para ocultar do participante a estrutura das frases alvo sob análise no estudo. Eles aparecem interpostos entre os pares alvo e normalmente compõem a maior parte dos estímulos apresentados.

Nos pares alvo (36), a sentença crítica retomava, com um pronome átono de objeto direto de terceira pessoa, um antecedente com função sintática de objeto (direto ou indireto). Essas sentenças foram retiradas do trabalho de Gelormini-Lezama e Almor (2011) e adaptadas para as listas de ambas as línguas, o português e o espanhol. Veja 


\section{Revista do SELL}

v. $4, n^{\circ} .1$

ISSN: $1983-3873$

um exemplo de par alvo, em português e em espanhol. O pronome de objeto direto, bem como seu referente, estão destacados nas frases:

(1a) Julieta falou com Pedro.

(1b) Julieta o convidou para uma festa.

(2a) Julieta habló con Pedro.

(2b) Julieta lo invitó a una fiesta.

Os pares distratores (72) foram especialmente criados e traduzidos para a pesquisa. Neles, a frase crítica retomava o antecedente com um pronome nulo ou um pronome pleno (átono ou tônico, conforme a função sintática e de acordo com a gramática normativa). Os antecedentes eram salientes, ou seja, tinham função de sujeito. Como, devido à sua característica não saliente, o objeto é recuperado pela memória menos facilmente que o sujeito, decidiu-se evitar esse tipo de antecedente nas frases distratoras, pois não se pretendia criar nesses pares dificultadores de processamento que pudessem mascarar a aferição de uma estimada maior dificuldade nos pares alvo, no caso do português brasileiro.

Em menor número, entretanto, foram utilizados pares de frases nos quais os antecedentes salientes (função de sujeito) e não salientes (função de objeto) da primeira frase foram coletivamente retomados pela anáfora presente na segunda frase, ou seja, a anáfora referia-se, ao mesmo tempo, ao sujeito e ao objeto. Veja um exemplo de par distrator, em português e em espanhol. O pronome anafórico, bem como seu referente, estão destacados nas frases:

(3a) Ângela teve uma filha.

(3b) Elas são muito parecidas.

(4a) Ángela tuvo una hija.

(4b) Ellas son muy parecidas.

A conformação descrita dos materiais, alvo e distratores, foi planejada de forma a procurar isolar, assim, o fator "pragmática" para avaliar a estrutura sob investigação: o pronome oblíquo como anáfora de objeto.

Criou-se, além disso, uma pergunta de resposta "sim" ou "não" para cada par da lista, a fim de que, ao se verificar a compreensão dos participantes, fosse mantida sua 


\section{Revista do SELL \\ v. $4, n^{\circ} .1$ \\ ISSN: $1983-3873$}

atenção durante todo o teste (RAYNER; WELL, 1996; FILIK; BARBER, 2011). Metade dessas perguntas tinha resposta positiva, e a outra metade, negativa. As perguntas apareciam no centro da tela do computador, após a apresentação de cada par de frases.

A apresentação aleatória dos pares alvo e dos distratores foi garantida por um programa do próprio rastreador ocular, que realizou esse trabalho para cada uma das sessões. Assim, seria evitado um possível efeito de ordem de apresentação (MAIA; CUNHA LIMA, 2012). Além disso, preparou-se uma lista extra composta por 5 pares de frases análogas às do experimento, para que os sujeitos se familiarizassem com o teste (YANG et al., 1999). Conforme previsto para todo o teste, todos os pares eram seguidos de perguntas de compreensão.

A coleta de dados ocorreu no laboratório de Psicolinguística da Faculdade de Letras da Universidade Federal de Minas Gerais. Utilizou-se a técnica de rastreamento ocular para acompanhamento dos movimentos oculares durante a leitura das frases. $O$ registro foi realizado pelo rastreador ocular Eye Link 1000'. As frases foram apresentadas, aos pares, na tela de um computador pessoal. A escolha pela apresentação em pares permitiria rastrear possíveis sacadas regressivas (movimentos oculares que permitem ao leitor voltar ao texto já lido - RAYNER; LIVERSEDGE, 2004) que as frases críticas pudessem suscitar em direção às respectivas primeiras sentenças. De acordo com Altmann (1994), esse parâmetro é, em grande medida, um índice de dificuldade de processamento.

\subsubsection{Tarefa}

Antes da calibração do rastreador ocular, os participantes receberam as instruções. Foi-Ihes dito que eles deveriam ler uma lista de sentenças, que seria apresentada na tela do computador aos pares, e que o objetivo do acompanhamento e do registro dos movimentos oculares pelo rastreador ocular era determinar o padrão desses movimentos entre as pessoas durante tarefas de leitura (RAYNER; WELL, 1996). Somado a isso, afirmou-se que o estudo buscava comparar esse padrão entre as línguas portuguesa e espanhola. Solicitou-se que a leitura fosse feita do modo mais natural possível, ou seja, nem muito rapidamente, nem muito lentamente (MAIA; CUNHA LIMA, 2012). Além disso, os participantes foram advertidos de que, após cada par de frases, eles teriam de

\footnotetext{
${ }^{1}$ Para especificações técnicas, consultar: 〈http://www.sr-research.com/mount_desktop.html〉.
} 


\section{Revista do SELL}

v. $4, n^{\circ} .1$

ISSN: $1983-3873$

responder a uma pergunta simples de compreensão (RAYNER; WELL, 1996). O teste durou aproximadamente 20 minutos para cada sujeito da pesquisa.

Para que os participantes se familiarizassem com a tarefa, fez-se um treinamento prévio ao efetivo teste com 5 pares de frases (e respectivas perguntas de compreensão) não pertencentes às listas do experimento, mas com estrutura gramatical análoga. $O$ teste era do tipo leitura autocadenciada. Os participantes deveriam, portanto, clicar no mouse para que novo par de frases fosse apresentado na tela do computador, solicitação explicada na fase das instruções. Quanto às questões de compreensão, os participantes foram orientados a clicar com o mouse em "sim", caso julgassem a resposta positiva, e em "não", caso a julgassem negativa. Após o treinamento, foi dito ao participante que o efetivo teste começaria assim que ele clicasse no mouse.

\subsubsection{Análise dos dados}

A leitura dos pares de frases alvo foi avaliada segundo os seguintes parâmetros de medida dos movimentos oculares, variáveis dependentes: tempo médio das fixações na palavra alvo (o pronome oblíquo como anáfora de objeto) e o número total de fixações. Os valores foram obtidos por grupo e posteriormente confrontados entre os grupos. Verificouse, com o teste-T de Student e o teste Chi-quadrado, se houve diferença estatisticamente significativa na comparação dos parâmetros entre as línguas.

\section{Resultados}

A figura 1 mostra a média (em milissegundos) do tempo total de fixações na palavra crítica, ou seja, no pronome oblíquo como anáfora de objeto direto, por língua. 


\section{Revista do SELL}

v. $4, n^{\circ} .1$

ISSN: $1983-3873$

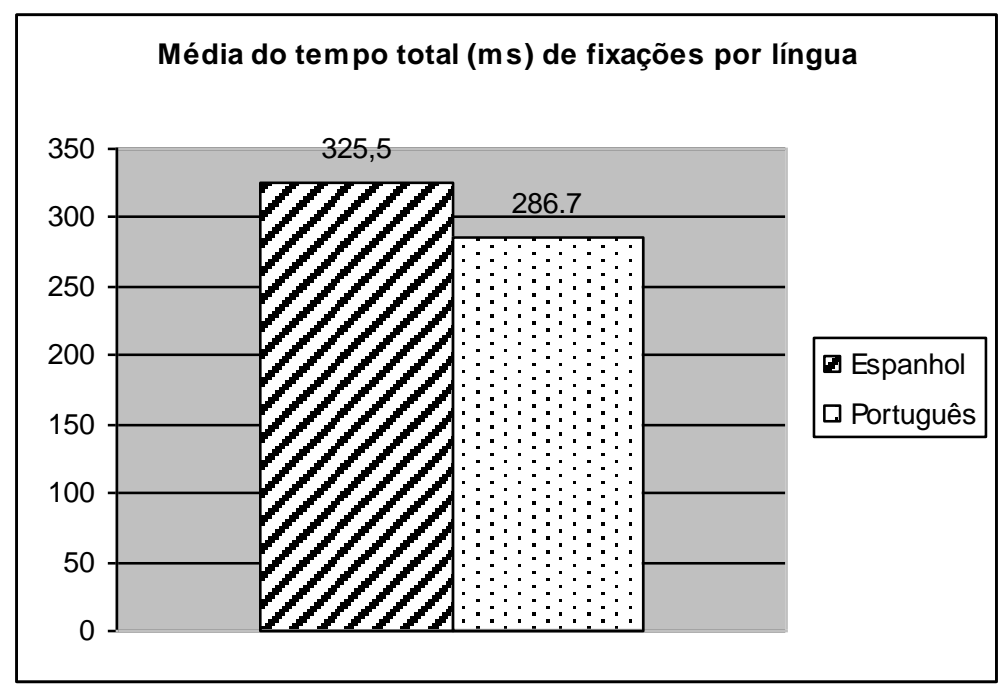

Figura 1 - Gráfico demonstrativo da média do tempo total de fixações na palavra crítica por língua.

Realizou-se o teste-T de Student para comparação dos tempos médios entre o português brasileiro e o espanhol. O resultado mostrou diferença significativa $(\mathrm{t}=$ 21,9535, df $=211$, valor de $p<2.2 e-16), p<0,0001$, indicando que os falantes do português brasileiro gastam em média menos tempo na leitura dos pronomes oblíquos que os falantes do espanhol.

Na figura 2, estão as médias do número de fixações na palavra crítica por língua.

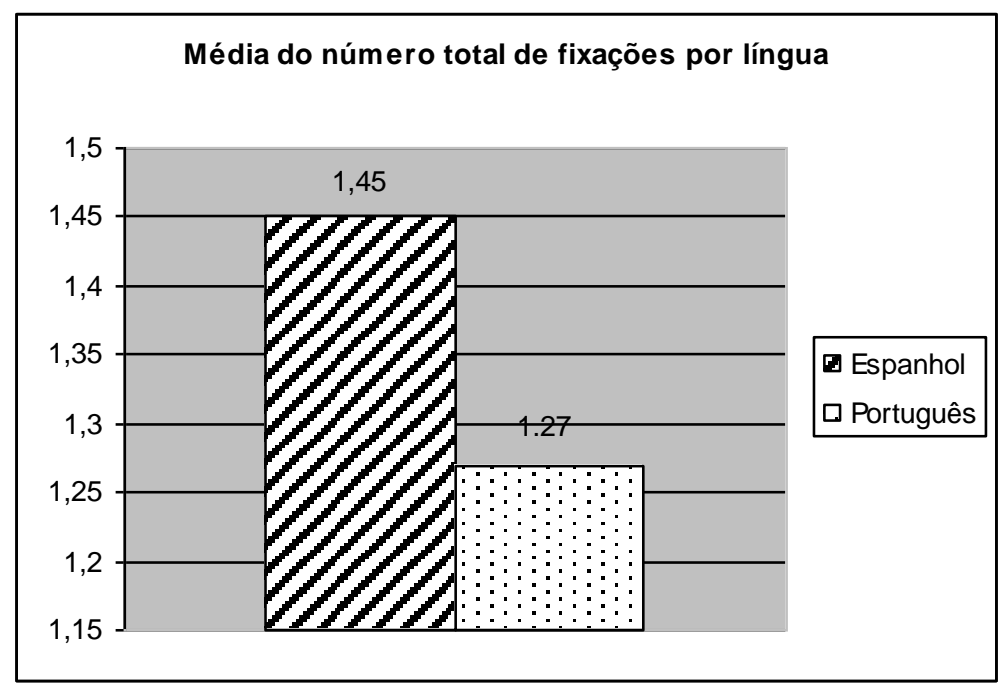

Figura 2 - Gráfico demonstrativo da média do número total de fixações na palavra crítica por língua. 


\section{Revista do SELL \\ v. $4, n^{\circ} .1$ \\ ISSN: $1983-3873$}

A comparação desse parâmetro entre o português brasileiro e o espanhol foi realizada com o teste Chi-quadrado. $O$ resultado $\left(X^{2}(81)\right.$, df $\left.(211), p=1\right)$ mostrou que não houve diferença significativa para essa variável.

\section{Discussão}

A análise dos parâmetros de movimentos oculares de tempo e número de fixações foi eficiente para observar o processamento de leitura do pronome oblíquo de objeto direto das duas línguas irmãs: o português brasileiro e o espanhol. $O$ experimento mostrou que o rastreamento ocular é ferramenta válida na investigação objetiva do processamento da linguagem, na comparação entre línguas.

Entretanto, os resultados obtidos foram surpreendentes, pois se mostraram totalmente opostos às expectativas. Esperava-se encontrar maior tempo médio de fixação no pronome oblíquo de objeto direto na leitura em português dos falantes brasileiros, quando comparados aos falantes de espanhol em sua respectiva língua materna. Essa estrutura se mostra marcada no português do Brasil, mesmo em sua forma escrita, como indicam os trabalhos de Cyrino (1996) e Oliveira (2010). Não foi esse, porém, o resultado verificado no estudo experimental realizado.

A destreza na leitura da palavra crítica pelos sujeitos brasileiros pode explicar-se pelo alto grau de escolaridade dos participantes. Todos são universitários ou profissionais com nível superior, mostrando, pois, habilidade com textos escritos na norma culta padrão. Maia e Cunha Lima (2012) observaram, em seu estudo experimental sobre o processamento de anáforas, que a norma culta referente ao emprego de pronomes oblíquos é inclusive esperada por esse tipo de leitor, transformando-se a incorreção (segundo a gramática normativa) de seu uso no texto, tal como na sua substituição por pronomes tônicos, em uma causa do efeito de estranhamento.

Não obstante, a principal incógnita dos resultados reside no fato de que os falantes do espanhol, completamente habituados, tanto na forma escrita quanto na oral de sua língua, à estrutura crítica testada (conforme MORENO GARCIA; FERNÁNDEZ, 2007), tenham empregado maior tempo médio na leitura desse item em relação aos falantes do português brasileiro. Embora o nível de escolaridade possa ter sido um fator atenuante do efeito de estranhamento da estrutura crítica no grupo de falantes do português brasileiro, esperava-se que a "naturalidade" dos falantes nativos de espanhol 


\section{Revista do SELL}

v. $4, n^{\circ} .1$

ISSN: $1983-3873$

ao lidar com essa estrutura, duplamente observada, na língua oral e na escrita, levasse a uma agilidade de processamento significativamente superior.

Diante da negativa dessa hipótese, procedeu-se à investigação dos possíveis fatores causais. Chegou-se à conclusão de que o tempo de inserção na nova língua, o português brasileiro, pode ter influenciado na forma como os falantes do espanhol percebem sua própria língua. Todos os participantes do experimento realizado vivem no Brasil há no mínimo 5 anos, sendo a média obtida 14,5 e o tempo máximo 28 anos.

Em um dos testes realizados por Sun, Morita e Stark (1985) em seu estudo comparado do processamento de leitura no inglês e no chinês, os pesquisadores verificaram um efeito de influência do inglês sobre o chinês. Os autores submeteram intercambistas chineses em país de língua inglesa à leitura de textos em sua língua materna. Observou-se ser maior o tempo de leitura para os chineses com maior tempo de intercâmbio (5 anos) em relação àqueles com menor tempo (2 anos ou menos). Se, sobre o chinês, língua não indoeuropeia, o inglês, que o é, foi capaz de exercer influência suficiente para que os falantes alterassem sua percepção da língua materna, acredita-se que a probabilidade de que tenha sido esse o fator deturpador dos resultados na presente pesquisa é coerente e tenha efeitos ainda mais fortes, visto serem as duas línguas irmãs.

Conclui-se, das análises, que a hipótese inicial não se anulou, apenas não tendo podido ser verificada devido à presença de um fator distrator: o bilinguismo. Tem-se, assim, uma nova questão de pesquisa: os efeitos do bilinguismo tardio no processamento da língua materna. Pesquisas futuras poderão vir a elucidar esse fator, promovendo o confronto entre línguas na busca de compreender os fenômenos ocorridos com essa classe particular de falantes, os bilíngues tardios.

Tradicionalmente, o estudo do bilinguismo focou a influência da língua materna sobre a língua estrangeira. As pesquisas nessa área são geralmente produções da Linguística Aplicada, tomando por questão de pesquisa fundamental o ensino de línguas estrangeiras. Vários são os pares linguísticos de língua materna e língua estrangeira estudados na literatura, tais como, respectivamente, o xerente (uma língua indígena) e o português (VIEIRA, 2009), o inglês e o português (SILVA, 2011), o inglês e o espanhol (OLSEN, 2012), o espanhol e o inglês (BARTO-SISAMOUT et al., 2009), o alemão no tcheco e no russo (SCHMIEDTOVÁ, 2011), o português e o espanhol (CAPILLA, 2010) e o espanhol e o português (CAPILLA, 2010).

Ainda, a grande preocupação nesse domínio gira em torno dos fenômenos da chamada interlíngua, uma fase intermediária no aprendizado da nova língua que merece 


\section{Revista do SELL}

v. $4, n^{\circ} .1$

ISSN: $1983-3873$

especial atenção para ser uma fase natural e provisória, e não um obstáculo intransponível, de forma a permitir que o aluno avance com sucesso em direção a maiores níveis de proficiência na língua estrangeira que está aprendendo. Muitos pesquisadores estudaram esses fenômenos, visando a entendê-los e a acompanhá-los no processo de aprendizagem (e.g., ORTIZ ALVAREZ, 2002; KÖPKE; SCHMID, 2004; ALBA QUIÑONES, 2009).

Apenas mais recentemente vem-se desenvolvendo uma linha de pesquisa que se dedica a compreender o processamento da linguagem por indivíduos bilíngues considerando a influência que a língua estrangeira poderia (e parece) ter sobre a percepção da língua materna. A psicolinguística, e suas técnicas experimentais, vem dando suporte a esse tipo de investigação, ajudando a registrar, com medidas mais precisas, o que a observação subjetiva já tinha permitido observar ou supor: a língua estrangeira é capaz de alterar a percepção dos falantes sobre a língua materna (SOUZA; OLIVEIRA, 2011; SOUZA, 2012; BROWN; GULLBERG, 2012).

As pesquisas nessa linha que considera a influência da língua estrangeira sobre a língua materna são ainda incipientes. Diferentes pares linguísticos, bem como diferentes estruturas linguísticas precisam ser testados, de forma a que se possa, no futuro, emitir uma hipótese de cunho mais geral sobre aspectos do funcionamento da mente bilíngue. Dessa forma, é desejável que se aprofundem os resultados do presente estudo, visando à melhor compreensão dos fenômenos encontrados e contribuindo para o avanço dessa linha mais recente de estudo do bilinguismo.

\section{Agradecimentos}

Aos participantes da pesquisa, pela disponibilidade e solicitude.

\section{Referências}

ADAMO, G. Todo podría ser diferente. In: ADAMO, G. et. al. Problemas de la traducción. Buenos Aires: Libros del Rojas, 2004. cap. 1, p.33-35.

ALBA QUIÑONES, V. El análisis de errores en el campo del español como lengua extranjera: algunas cuestiones metodológicas. Revista Nebrija de Lingüística Aplicada, v. 5, n. 3, p. 1-16, 2009. Disponível em: <http://www.nebrija.com/revistalinguistica/revista_5/articulos_n5/quinones_alba.pdf>. Acesso em: 17 jun. 2012. 


\section{Revista do SELL}

v. $4, n^{\circ} .1$

ISSN: $1983-3873$

ALMOR, A. Noun-phrase anaphora and focus: the informational load hypothesis. Psychological Review, v. 106, n. 4, p. 748-765, 1999. Disponível em: http://alab.psc.sc.edu/images/Publications/Almor_PsychRev_1999.pdf. Acesso em: 04 fev. 2012.

ALTMANN, G. T. M. Regression contingent analyses of eye movements during sentence processing: a reply to Rayner and Sereno. Memory \& Cognition, v. 22, n. 3, p. 286-290, 1994. Disponível em: <http://www.springerlink.com/content/76660l11h892v6u5/>. Acesso em: 22 fev. 2012.

BARTO-SISAMOUT, K.; NICOL, J.; WITZEL, J.; WITZEL, N. Transfer effects in bilingual sentence processing. 1 Arizona Working Papers in SLA \& Teaching, n. 16, p. 1-26, 2009. Disponível em: <http://slat.arizona.edu/sites/slat/files/page/awp16barto-sisamoutetal.pdf>. Acesso em: 14 jun. 2012.

BROWN, A.; GULLBERG, M. Multicompetence and native speaker variation in clausal packaging in Japanese. Second Language Research, v. 28, n. 4, p. 415-442, 2012. Disponível em: <http://dedikasimuslim.files.wordpress.com/2012/11/second-languageresearch-2012-brown-415-42_dedikasimuslim-wordpress-com.pdf>. Acesso em: 20 set. 2012.

CAPILLA, M. C. C. O efeito da língua materna na aquisição de línguas próximas. Revista Intercâmbio dos Congressos de Humanidades, 2010. Disponível em: <http://unb.revistaintercambio.net.br/24h/pessoa/temp/anexo/1/299/246.pdf>. Acesso em: 17 jun. 2012.

CAPILLA, M. C. C. Espanhol e português em contato: o atrito da L1 de imigrantes espanhóis no Brasil. Revista Intercâmbio dos Congressos de Humanidades, 2010.

Disponível em: $<$ http://unb.revistaintercambio.net.br/24h/pessoa/temp/anexo/1/176/156. pdf>. Acesso em: 17 jun. 2012.

COELHO, F. S. A língua portuguesa no Brasil. Cadernos do CNLF, Rio de Janeiro, n. 4, 2001. (Série V) Disponível em: <http://www.filologia.org.br/vcnlf/anais\%20v/civ4_01.htm>. Acesso em: 18 jan. 2012. 


\section{Revista do SELL}

v. $4, n^{\circ} .1$

ISSN: $1983-3873$

COSTA, A.; MATOS, G.; LUEGI, P. Using eye-tracking to study anaphoric relations processing in European Portuguese. Journal of Eyetracking, Visual Cognition and Emotion, v. 1, n. 1, p. 50-58, 2011 . Disponível em: <http://revistas.ulusofona.pt/index.php/JETVCE/article/view/2054/1577>. Acesso em: 15 jan. 2012.

CYRINO, S. M. Observações sobre a mudança diacrônica no português do Brasil: objeto nulo e clíticos. In: ROBERTS, I.; KATO, M. (org.). Português brasileiro: uma viagem diacrônica. Campinas: UNICAMP, 1996. cap. V, p.163-184.

ECO, U. Decir casi lo mismo. Barcelona: Debolsillo, 2009. 544 p.

FERNÁNDEZ, E. M.; CAIRNS, H. S. Fundamentals of Psycholinguistics. Nova Jersey: John Wiley \& Sons, 2010. $336 \mathrm{p}$.

FILIK R.; BARBER, E. Inner speech during silent reading reflects the reader's regional accent. PLOS ONE, v. 6, n. 10, p. 1-5, oct. 2011. Disponível em: <http://www.plosone.org/article/info\%3Adoi\%2F10.1371\%2Fjournal.pone.0025782>. Acesso em: 17 jan. 2012.

GELORMINI-LEZAMA, C.; ALMOR, A. Repeated names, overt pronouns, and null pronouns in Spanish. Language and Cognitive Processes, v. 26, n. 3, p. 437-454, 2011.

GERNSBACHER, M. A. Mechanisms that improve referential access. Cognition, n. 32, p. 99-156, 1989. Disponível em: <http://psych.wisc.edu/lang/pdf/Gernsbacher_ReferentialAccess_Cog_1989.pdf>. Acesso em: 04 fev. 2012.

GORDON, P. C. et al. Pronouns, names and the centering of attention in discourse. Cognitive Science, n.17, p. 311-347, 1993.

HENDERSON, J. M.; FERREIRA, F. Scene perception for psycholinguists. In:

(Ed.). The interface of language, vision, and action: eye movements and the visual world. New York: Psychology Press, 2004. cap. 1, p. 1-58.

HUETTIG, F.; ALTMANN, G. T. M. Word meaning and the control of eye fixation: semantic competitor effects and the visual world paradigm. Cognition, n. 96, p. B23-B32, 2005. Disponível em: <http://pubman.mpdl.mpg.de/pubman/item/escidoc:57322:2/component/escidoc:57323/Hu ettig_2005_word.pdf>. Acesso em: 17 jan. 2012. 


\section{Revista do SELL}

v. $4, n^{\circ} .1$

ISSN: $1983-3873$

JAINTA S.; KAPOULA Z. Dyslexic children are confronted with unstable binocular fixation while reading. PLOS ONE, v. 6, n. 4, p. 1-10, apr. 2011. Disponível em: <http://www.plosone.org/article/info\%3Adoi\%2F10.1371\%2Fjournal.pone.0018694>.Acess o em: 17 jan. 2012.

KLEIN, A. I.; BULLA, J. P. Eye-tracking e a linguística: aplicações e interfaces. Letrônica, v. 3 , n. 2 , p. 235-249, 2010 . Disponível em: <http://revistaseletronicas.pucrs.br/ojs/index.php/letronica/article/viewFile/7606/6255> Acesso em: 12 out. 2011.

KÖPKE, B.; SCHMID, M. S. First language attrition: the next phase. In: SCHMID, M.S.; KÖPKE, B.; KEIJZER, M.; WEILEMAR, L. (Ed). First Language Attrition: Interdisciplinary Perspectives on Methodological Issues. Amsterdam/Philadelphia: John Benjamins, 2004. p. 1-43. Disponível em: <http://www.let.rug.nl/languageattrition/Papers/Kopke\%20\&\%20Schmid\%202004.pdf>. Acesso em: 14 jun. 2012.

MACEDO, E. C. et al. Processos perceptuais e cognitivos na leitura de palavras: propriedades dos movimentos oculares. Psicol. Esc. Educ. (Impr.), Campinas, v. 11, n. 2, p. 275-283, jul./dez. $2007 . \quad$ Disponível em: $<$ http://www.scielo.br/scielo.php?script=sci_arttext\&pid=S141385572007000200007\&lng=en\&nrm=iso>. Acesso em: 10 jan. 2012.

MAIA, J. C.; CUNHA LIMA, M. L. Referenciação e técnicas experimentais: aspectos metodológicos na investigação do processamento correferencial em português brasileiro. 2012. No prelo.

MCDONALD, S. A.; SHILLCOCK, R. C. Eye movements reveal the on-line computation of lexical probabilities during reading. Psychological Science, v. 14, n. 6, p. 648-652, nov. 2003. Disponível em: <http://wexler.free.fr/library/files/mcdonald\%20\%282003\%29\%20eye\%20movements\%20r eveal\%20the\%20online\%20computation\%20of\%20lexical\%20probabilities\%20during\%20r eading.pdf>. Acesso em: 17 jan. 2012.

MORENO GARCIA, C.; FERNÁNDEZ, I. G. M. E. Usos y significados de los pronombres átonos: objeto directo e indirecto. In: Gramática contrastiva del español para brasileños. Alcobendas: Sociedad General Española de Librería, 2007. un. 4, p. 47-55.

OGUSUKO, M. T.; LUKASOVA, K.; MACEDO, E. C. Movimentos oculares na leitura de palavras isoladas por jovens e adultos em alfabetização. Psicologia: Teoria e Prática, v. 


\section{Revista do SELL}

v. $4, n^{\circ} .1$

ISSN: $1983-3873$

10, n. $1, \quad$ p. 113-124, 2008. Disponível em: <http://pepsic.bvsalud.org/pdf/ptp/v10n1/v10n1a09.pdf>. Acesso em: 17 jan. 2012.

OLIVEIRA, S. M. A ordem dos clíticos no Português Brasileiro do século XIX. Eletras, v. 20, n.20, p. 25-36, 2010. Disponível em: $<$ http://www.utp.br/eletras/ea/eletras20/textos/Artigo_20.3_A_ordem_dos_cliticos_SOLAN GE_MENDES_OLIVEIRA.pdf>. Acesso em: 18 jan. 2012.

OLSEN, M. K. The L2 Acquisition of Spanish Rhotics by L1 English Speakers: The Effect of L1 Articulatory Routines and Phonetic Context for Allophonic Variation. Hispania, v. 95, n. $1, \quad$ p. $65-82, \quad 2012 . \quad$ Disponível em: $<$ http://muse.jhu.edu/journals/hpn/summary/v095/95.1.olsen.html>. Acesso em: 14 jun. 2012.

ORTIZ ALVAREZ, M. L. A transferência, a interferência e a interlíngua no ensino de línguas próximas.. In: CONGRESO BRASILENO DE HISPANISTAS, 2., 2002, São Paulo. Anais... Rio de Janeiro: Associação Brasileira de Hispanistas, 2002. Disponível em: $<$ http://www.proceedings.scielo.br/scielo.php?script=sci_arttext\&pid=MSC0000000012002 000100039\&lng=en\&nrm=abn>. Acesso em: 17 jun. 2012.

PENNY, R. A history of the Spanish language. Cambridge: Cambridge University Press, 1992. $319 \mathrm{p}$.

RAYNER et al. The effect of word predictability on the eye movements of Chinese readers. Psychonomic Bulletin \& Review, v. 12, n. 6, p. 1089-1093, 2005. Disponível em: <http://www.springerlink.com/content/441325655k834773/fulltext.pdf>. Acesso em: 17 jan. 2012.

RAYNER, K.; LIVERSEDGE, S. P. Visual and linguistic processing during eye fixations in reading. In: HENDERSON, J. M.; FERREIRA, F. (Ed.). The interface of language, vision, and action: eye movements and the visual world. New York: Psychology Press, 2004. cap. 1, p. 59-104.

RAYNER, K.; WELL, A. D. Effects of contextual constraint on eye movements in reading: a further examination. Psychonomic Bulletin \& Review, v. 3, n. 4, p. 504-509, 1996. Disponível em: <http://www.springerlink.com/content/q3385xr2733k10l7/>. Acesso em: 17 jan. 2012.

RODRíGUEZ, A. M. Aspectos comparativos entre o espanhol e o português. In: SEMANA NACIONAL DE ESTUDOS FILOLÓGICOS E LINGUÍSTICOS (SENEFIL), 7., 2004, Rio de Janeiro. Anais... Rio de Janeiro: UERJ, 2004. Disponível em: <http://www.filologia.org.br/viisenefil/01.htm>. Acesso em: 20 jan. 2012. 


\section{Revista do SELL}

v. $4, n^{\circ} .1$

ISSN: $1983-3873$

SAEZ HERMOSILLA, T. El concepto de fidelidad y sus implicaciones. In: . El sentido de la traducción: reflexión y crítica. León: Universidad de León, Secretariado de Publicaciones, 1994. p.19-21.

SCHMIEDTOVÁ, B. Do L2 speakers think in the L1 when speaking in the L2? VIAL, n. 8, 2011. Disponível em: <http://www.idf.uniheidelberg.de/mitarbeiter/schmiedtova/unterverzeichnis1/Vial-2011-B.Schmiedtova.pdf>. Acesso em: 14 jun. 2012.

SILVA, A. G. 2011. L1, um scaffolding para a aquisição de L2: análise numa perspectiva interacionista. Revista Entreletras Revista do Curso de Mestrado em Ensino de Língua e Literatura da UFT, n. 3, 2011. Disponível em: <http://www.uft.edu.br/pgletras/revista/capitulos/11._I1,_um_scafoolding_para_a_aquisica o_de_l2.2.pdf>. Acesso em: 14 jun. 2012.

SOUZA, R. A. Two languages in one mind and the online processing of causatives with manner-of-motionverbs. ReVEL, n. 6, 2012. Disponível em: <http://www.revel.inf.br/files/762fc100ecfdf29974f74a137732cdfd.pdf>. Acesso em: 20 set. 2012.

SOUZA, R. A., OLIVEIRA, F. L. P. Is knowledge of a non-dominant L2 activated by bilinguals using their dominant L1? Insights from an on-line psycholinguistic study. Organon, n. 51, p. 103-128, 2011.

SUN, F.; MORITA, M.; STARK, L. W. Comparative patterns of reading eye movement in Chinese and English. Attention, Perception, \& Psychophysics, v. 37, n. 6, p. 502-506, 1985. Disponível em: <http://www.springerlink.com/content/6r7k345387j14653/fulltext.pdf>. Acesso em: 15 jan. 2012.

TANENHAUS et al. Integration of visual and linguistic information in spoken language comprehension. 1995. Science, v. 268, n. 5217, p. 1632-1636, 1995. Disponível em: <http://www.bcs.rochester.edu/people/mtan/mtan1995.pdf>. Acesso em: 17 jan. 2012.

TRAUZETTEL-KLOSINSKI et al. Eye movements in German-speaking children with and without dyslexia when reading aloud. Acta Ophthalmologica, v. 88, n. 6, p. 681-691, 2010. Disponível em: <http://onlinelibrary.wiley.com/doi/10.1111/j.1755-3768.2009.01523.x/pdf>. Acesso em: 17 jan. 2012. 


\section{Revista do SELL}

v. $4, n^{\circ} .1$

ISSN: $1983-3873$

VIEIRA, R.P.F. Um olhar sobre o papel da L1 no processo de aquisição do português escrito como L2. Revista Eutomia, ano II, n. 1, p. 603-623, 2009. Disponível em: <http://www.revistaeutomia.com.br/volumes/Ano2-Volume1/linguistica-artigos/Um-Olharsobre-o-Papel-da-L1-no-Processo-de-Aquisicao-do-Portugues-Escrito-como-L2_RaquelPeixoto-Ferreira.pdf>. Acesso em: 13 jun. 2012.

YANG et al. Comprehension of referring expressions in Chinese. Language and Cognitive Processes, v. 14, n. 5/6, p. 715-743, 1999. Disponível em: <http://www.unc.edu/ pcg/personal/documents/YangGordonHendrickWuLCP1999.pdf>. Acesso em: 15 jan. 2012.

YOKOMIZO et al. Movimentos sacádicos durante leitura de texto em crianças e universitários bons leitores. O Mundo da Saúde, v. 32, n. 2, p. 131-138, 2008. Disponível em: <http://www.scamilo.edu.br/pdf/mundo_saude/59/131a138.pdf>. Acesso em: 11 jan. 2012. 